\title{
Peluang Dan Tantangan Pengembangan Layanan Wisata Kapal Pesiar (Cruise) Di Pelabuhan Belawan Medan
}

\author{
I Made Adhi Gunadi \\ Fakultas Pariwisata Universitas Pancasila, Srengseng Sawah, Jagakarsa, Jakarta 12 640, Indonesia \\ made.gunadi@univpancasila.ac.id
}

\section{ABSTRACT}

Article history:

Submitted: May 22, 2020

Reviewed: June 10, 2020

Accepted: June 18, 2020

Published: June 30, 2020

Keywords: cruise tourism, port management, sailing traffic, Indonesia cruise.

Kata kunci: wisata kapal pesiar, manajemen pelabuhan, lalulintas pelayaran, cruise Indonesia
As an archipelago, Indonesia has huge potential to become a marine tourism destination, including cruise tourism. Cruise tourism is a very segmented tour and has developed into a complete, complex tourism business and at the same time being able to make a significant and promising contribution in the global tourism industry. This study seeks to assess the readiness of the Belawan port in providing support services to the complex cruise tourism. As an analysis tool, the approach of Manzano (2014) was used. The results of the study show that Belawan already has sufficient readiness to support cruise tourism, but also faces significant challenges so that the services provided can run continuously.

\section{ABSTRAK}

Sebagai negara kepulauan, Indonesia memiliki potensial sangat besar menjadi destinasi wisata bahari, termasuk wisata kapal pesiar. Wisata kapal pesiar merupakan wisata yang sangat segmented dan telah berkembang menjadi usaha wisata yang lengkap, kompleks sekaligus mampu memberikan kontribusi yang cukup signifikan dan menjanjikan dalam industry pariwisata global. Penelitian ini berusaha mengkaji kesiapan pelabuhan Belawan dalam memberikan dukungan layanan kepada wisata kapal pesiar yang kompleks tersebut. Sebagai alat analisa, digunakan pendekatan dari Manzano (2014). Hasil kajian menunjukkan bahwa Belawan telah memiliki cukup kesiapan dalam mendukung wisata kapal pesiar, namun juga menghadapi tantangan besar agar layanan yang diberikan dapat berjalan secara berkesinambungan.

Copyright @ 2019 Politeknik Negeri Samarinda. All rights reserved. 


\section{Pendahuluan}

Wisata kapal pesiar telah berkembang dari yang semula hanya diikuti sebagian kecil penumpang samudera, berkembang menjadi bisnis liburan yang lengkap dan kompleks, termasuk melibatkan semua sektor industri perjalanan yang berbeda (Brida \& Zapata, 2010) seperti pengelola destinasi, pengelola pelabuhan, agen perjalanan wisata, jasa-jasa pariwisata, pemasok kuliner dan penyedia layanan profesional lainnya. Berwisata dengan kapal pesiar dapat dianggap sebagai liburan yang sempurna dimana wisatawan dapat menikmati aktivitas wisata air dan darat sekaligus. Ward (2015) bahkan menyatakan hal berikut: Pelayaran wisata dengan kapal pesiar merupakan pelarian dari tekanan kehidupan di darat. Sebagian besar kegiatan wisata di kapal pesiar merupakan kegiatan prabayar, bebas repot, dan yang sangat penting, bebas kejahatan. Wisatawan pun hanya perlu berkemas dan membongkar koper satu kali saja untuk menikmati beragam aktivitas tersebut. Wisatawan tak perlu harus membuat pilihan kegiatan, tidur di ranjang yang sama setiap malam, dan sepanjang rute pelayaran kapal dapat menikmati pemandangan yang berbeda.

Secara global, lebih dari 22 juta orang naik kapal pesiar pada tahun 2014, dan semua kapal baru menawarkan atraksi dan fasilitas terkini yang bertujuan memperluas pasar. Pada akhir 2014, lebih dari 50 kapal berukuran lebih dari 100.000 ton telah beroperasi, sementara lebih dari 20 kapal baru berbagai ukuran telah dijadwalkan untuk pengiriman antara Januari 2016 dan akhir 2019. Pada 2016, dari tujuh kapal baru dijadwalkan untuk diluncurkan dengan kapasitas terkecil adalah Viking Ocean Cruises (47.000 ton) dengan 928 penumpang, sementara yang terbesar adalah Royal Caribbean International (225.000 ton) dengan 5.400 penumpang. Beberapa kapal baru adalah kloning dari seri yang sama dalam hal ukuran, tata letak, dan konfigurasi, untuk membantu menekan biaya kontruksi. Dengan perkecualian dua kapal AIDA Cruises yang sedang dibangun oleh Mitsubishi Heavy Industries, Jepang, untuk diperkenalkan pada 2015 dan 2016, semua kapal sedang dibangun oleh galangan kapal spesialis di Prancis, Finlandia, Jerman dan Italia (Ward, 2015).
Asosiasi Pelayaran Internasional (CLIA) memperkirakan ada 24,2 juta orang berlayar pada 2016. Amerika Serikat adalah negara yang menjadi segmen pasar kapal pesiar terbesar di dunia dengan 51,7\% penumpang global pada 2014 seperti yang dilaporkan oleh CLIA. Ini kemungkinan besar karena Miami merupakan sentra utama untuk kapal pesiar menuju Karibia, yang menyumbang $37,3 \%$ dari semua tujuan pelayaran 2014. Ketika ekonomi terus tumbuh dan pengangguran semakin menurun, tingkat pendapatan akan naik. Akibatnya, lebih banyak orang yang memiliki uang untuk kegiatan senggang dan wisata, termasuk perjalanan dengan kapal pesiar. Selain itu, meningkatnya populasi warga AS yang menua lebih lanjut berkontribusi terhadap permintaan kapal pesiar karena target pasar utama wisata kapal pesiar adalah individu yang berusia di atas 25 tahun dengan pendapatan tahunan setidaknya $\$$ 40.000. Selain itu, perkiraan CLIA bahwa $20,0 \%$ dari pasar kapal pesiar terdiri dari individu-individu pensiunan. Sebagai hasil dari populasi yang menua dan meningkatnya pendapatan, permintaan kapal pesiar akan meningkat secara substansial di tahun-tahun mendatang (Soshkin, 2015). Ada juga survei liburan keseluruhan terbaik yang dilakukan oleh CLIA pada Februari 2015, hasilnya adalah $42 \%$ responden memilih kapal crusie sebagai liburan wisata terbaik, lalu $14 \%$ liburan di darat, $9 \%$ dari resor all-in dan sisanya di bawah $6 \%$.

Wisata cruises telah berkembang menjadi salah satu segmen industri wisata internasional yang paling dinamis dan pesat pertumbuhannya, seiring dengan pertumbuhan jumlah penumpang cruise (Sun et al., 2011). Pada 2016, prospek industri pelayaran terus menguat dengan 24,2 juta penumpang dan tingkat pertumbuhan tahunan rata-rata $4,5 \%$ untuk periode 2009 - 2016.

Pemain utama dalam industri kapal pesiar per November 2015 adalah Carnival Corporation (Karnaval) dengan pangsa pasar 18,9\%, Royal Caribbean Cruises Ltd. dengan $11,8 \%$, Norwegian Cruise Line Holdings Ltd. dengan $8,0 \%$, dan lainnya dengan $61,3 \%$. Info pangsa pasar bisa berbeda dari laporan ke laporan lain karena terjadi banyak merger dan akuisisi antar perusahaan operator kapal pesiar. 
Perluasan kapasitas pelayaran berdampak pada volume kunjungan di semua tujuan secara global. Industri pelayaran di Asia tumbuh 53\% per tahun pada tahun 2016, dan saat ini berada di 4 jalur pelayaran global terbesar dengan 9,2\% dari total kapasitas (ALBD). Ada penyebaran pergeseran yang dramatis di wilayah Asia Timur dengan perubahan $99 \%$ di tahun 2016, pada periode yang sama wilayah Asia Timur menjadi tuan rumah bagi $63,5 \%$ pelayaran cruise dengan $71,3 \%$ penumpang asal Asia. Beberapa negara di Asia yang menerima volume panggilan terbesar disajikan berikut: Jepang, Cina, Korea Selatan, Vietnam dan Malaysia menjadi tuan rumah pelayaran cruise terbesar dengan menerima lebih dari 400 kunjungan pada 2016, sementara Indonesia masih di peringkat 10 dengan 172 kunjungan pelayaran cruise. Tabel berikut menyajikan outlook industri wisata cruise pada 2016.

Tabel 1. Outlook industri wisata cruise di Asia, 2016

\begin{tabular}{|lc|}
\multicolumn{1}{|c|}{ Negara } & Pertumbuhan \\
\hline China & 183 \\
\hline Jepang & 136 \\
\hline Korea Selatan & 98 \\
\hline Vietnam & 47 \\
\hline Taiwan & 34 \\
\hline Singapura & 5 \\
\hline Hong Kong & -8 \\
\hline Indonesia & $\mathbf{- 1 2}$ \\
\hline Thailand & -22 \\
\hline Malaysia & -27 \\
\hline
\end{tabular}

Pertumbuhan China berada di laju tercepat dengan peningkatan $183 \%$ dibanding tahun sebelumnya (year on year). Pertumbuhan industri wisata cruise di Indonesia pada 2016 adalah minus $12 \%$ dibanding tahun sebelumnya. Pertumbuhan ini jelas berada jauh di bawah pertumbuhan industri cruise di China, Jepang, Korsel, Vietnam, Taiwan dan Singapore, namun masih lebih baik dari pertumbuhan cruise di Malaysia dan Thailand.

\section{Wisata Cruise di Indonesia}

Seiring dengan perkembangan kapal dan jumlah penumpangdi tingkat global, Indonesia juga memiliki harapan besar untuk menjadi bagian dari industri wisata cruise ini.
Masih terbatasnya penelitian dan fakta bahwa infrastruktur pariwisata bahari belum berkembang seperti pariwisata lainnya adalah masalah utama dalam industri wisata pelayaran. Di sisi lain, Indonesia juga memiliki potensi besar dan keunggulan komparatif bagi wisata cruise.

\section{Keunggulan Komparatif \& Kompetitif}

Indonesia dianugerahi lokasi dan iklim yang menarik dan sangat mendukung bagi pengembangan wisata bahari. Terdiri dari lima pulau besar dan 13.677 pulau kecil (sekitar 6.000 di antaranya berpenghuni) membentuk busur antara Asia dan Australia dengan total luas $1.919 .440 \mathrm{~km}$ persegi $(741.100 \mathrm{mil}$ persegi). Membentang $5.271 \mathrm{~km}(3.275 \mathrm{mi})$ dari timur ke barat dan $2.210 \mathrm{~km}(1.373 \mathrm{mi})$ dari utara ke selatan. Lima pulau utama adalah Sumatra; Jawa; Kalimantan; Sulawesi; dan Papua. Indonesia memiliki batas-batas daratan dengan Malaysia (di Kalimantan), Papua Niugini (di Papua), dan Timor Leste (di Timor). Sementara batas laut di utara oleh Laut Cina Selatan, di timur laut oleh Samudra Pasifik, dan di barat daya oleh Samudra Hindia. Total panjang batas tanah Indonesia adalah $2.830 \mathrm{~km}(1.758 \mathrm{mi})$. Garis pantainya adalah $54.716 \mathrm{~km}$ (33.999 mi).

Berada dalam lintasan garis khatulistiwa, Indonesia memiliki iklim tropis yang dicirikan oleh curah hujan lebat, kelembaban tinggi, suhu tinggi, dan angin kencang. Kelembaban rata-rata adalah $82 \%$. Di permukaan laut, suhu tahunan rata-rata sekitar $25-27^{\circ}$ C. Secara umum, kondisi geografis dan iklim tersebut sangat sesuai bagi wisatawan yang ingin merasakan suhu dan iklim yang berbeda sambil berharap bahwa perbedaannya masih ramah terhadap adaptasi tubuh manusia mereka, karena karakteristik pariwisata adalah mencicipi sesuatu yang berbeda.

Selanjutnya, menurut ILO (2012), kekuatan Indonesia termasuk:

\section{Wisata sosial-budaya}

Indonesia diuntungkan dari aset budaya, warisan pusaka (heritage) dan budaya yang hidup dengan kearifan lokal dan tradisi unik mereka. Semangat antusias untuk melestarikan budaya lokal semakin menguat. Peningkatan kebanggaan dalam budaya, 
revitalisasi budaya, peningkatan konservasi dan pemulihan situs warisan budaya terbukti, antara lain oleh Kementerian Pekerjaan Umum dengan Program Perencanaan Kota Warisannya.

\section{Lingkungan}

Kearifan lokal di beberapa daerah telah terbukti efektif dalam perlindungan terhadap sumber daya alam. Kesadaran akan pentingnya pembangunan yang ramah lingkungan semakin meningkat. Kelompok dan aktivis lingkungan untuk pembangunan hijau dan gaya hidup hijau muncul di provinsi-provinsi terkemuka seperti Bali, Jakarta, Jawa Barat, dan lainnya. Di banyak destinasi wisata, Indonesia memiliki dan bisa menujukkan banyak kasus praktik terbaik (best practices) dalam bidang ekowisata.

\section{Keanekaragaman hayati dan budaya}

Kekayaan dan keragaman alam Indonesia telah lama menjadi kekuatan Indonesia sebagai dasar untuk pengembangan pariwisata. Fenomena dan fitur alam seperti: gunung berapi dan kaldera, danau, gua, hutan hujan tropis, sabana, sungai, pantai, kehidupan bawah air dan acara budaya, festival, kerajinan serta warisan adalah sumber daya pariwisata Indonesia yang masih menunggu pengelolaan dan kemasan kreatif.

\section{Perencanaan Destinasi}

Sebagian besar daerah telah menyadari kebutuhan dan pentingnya perencanaan untuk pengembangan pariwisata. Di tingkat nasional, Rencana Induk Pariwisata Nasional telah disahkan. Pemerintah juga telah menetapkan lima destinasi sebagai Destinasi Super Prioritas dan enam destinasi lainnya sebagai Destinasi Prioritas untuk dikembangkan. Tujuan wisata terkemuka seperti Bali dan Jakarta telah mengintegrasikan rencana pengembangan pariwisata mereka ke dalam rencana induk tata ruang yang komprehensif.

\section{Dukungan politik}

Pariwisata Indonesia didukung oleh kemauan politik yang kuat, antara lain ditunjukkan dengan terbitnya Instruksi Presiden Nomor 16 - 2005 dan peningkatan anggaran nasional untuk Kementerian Pariwisata dan Ekonomi Kreatif. Saat ini pemerintah mengumumkan bahwa salah satu sektor prioritas Indonesia adalah pariwisata. Dengan sendirinya, saat ini pemerintah menyediakan porsi anggaran yang signifikan di sektor pariwisata dan pendukungnya.

Menurut CLIA (2014), tujuan pelayaran utama di Indonesia adalah Bali, Komodo, Semarang, Lombok, dan Jakarta. Semua pelabuhan di Indonesia ditampilkan terutama sebagai tujuan transit. Indonesia menyumbang sekitar 5\% dari total hari kunjungan penumpang dan awak (180.116) di seluruh Asia Tenggara dengan hari-hari kunjungan penumpang transit mencakup $78 \%$ dari total. Penumpang transit menghabiskan rata-rata US \$ 147 (Rp 1,89 juta) per hari kunjungan dengan pengeluaran untuk kunjungan darat dan akuntansi belanja ritel sekitar $67 \%$ dari total. Pengeluaran langsung oleh jalur pelayaran dan penumpang serta kru mereka berjumlah US \$ 36,9 juta (Rp 475 triliun) dengan penumpang menyumbang $79 \%$ dari total, dan jalur pelayaran sebesar $16 \%$. Pengeluaran langsung menghasilkan US \$77,8 juta (Rp 1,003 triliun) dalam output dan 948 pekerjaan penuh dan paruh waktu membayar US \$ 16,3 juta (Rp 210 triliun) sebagai kompensasi karyawan. Secara keseluruhan, dampak ekonomi di Indonesia menyumbang sekitar 3\% dari dampak output dan kesempatan kerja di seluruh Asia Tenggara. Industri pelayaran secara langsung mempekerjakan 15.532 warga Indonesia. Hampir semua karyawan ini bekerja sebagai awak kapal pesiar di atas kapal. Termasuk para karyawan kapal pesiar ini, total dampak pekerjaan meningkat menjadi 16.480 pekerjaan dengan bayaran US \$ 146 juta (Rp 1.889 triliun) sebagai kompensasi di Indonesia.

Meskipun Indonesia memiliki semua kekuatan komparatif dan kompetitif untuk menjadi bagian dari industri pelayaran, jumlah panggilan masih rendah dan fakta bahwa Indonesia hanya menyumbang sekitar 5\% dari total hari kunjungan penumpang dan awak (180.116) di seluruh Asia Tenggara menjadi masalah utama. Ideologi maritim kemudian diperkenalkan untuk menjelaskan masalah ini, meskipun penerimaan ideologi ini masih lambat. Selanjutnya, pemerintah sudah memulai program tol laut sebagai perwujudan dari Nawacita. Indonesia dengan Nawacita menganggap industri kapal pesiar sebagai 
sumber potensial pertumbuhan ekonomi, yang juga memperkuat identitas Indonesia dalam ideologi maritim. Indonesia telah mulai menambahkan pelabuhan panggilan baru ke rencana perjalanan yang ada dan yang baru dalam program laut tol, dan menyediakan aksesibilitas yang lebih baik ke pelabuhan embarkasi dalam program pengembangan infrastruktur. Perkembangan ini telah memberikan harapan bagi semua pelaku industri pariwisata.

Kapal pesiar adalah peluang investasi yang menarik yang diuntungkan dari pengembangan industri maritim. Industri kapal pesiar diharapkan tumbuh dan menjadi tulang punggung pariwisata masa depan karena kapal dapat melayani laut dalam, pantai, danau, dan sungai seperti yang ditemukan di kepulauan Indonesia. Bersama dengan asetnya dan dukungan pemerintah dalam infrastruktur dan keamanan, perjalanan yang menyenangkan di laut Indonesia dapat diwujudkan. Sektor pariwisata adalah industri strategis yang harus dikembangkan bersama dengan pelabuhan dan program pengembangan infrastruktur lainnya.

Selain ideologi maritim, terdapat beberapa faktor penentu lain untuk menarik jalur pelayaran internasional ke pelabuhan panggilan tertentu. selanjutnya.

\section{Faktor Penentu Lalu-lintas Kapal Pesiar}

Ketika sebuah kapal pesiar memasuki pelabuhan, banyak wisatawan akan turun berkunjung ke darat. Wisatawan akan membeli produk atau layanan lokal hingga menciptakan efek berganda dan menjadi sumber pertumbuhan ekonomi dan berkontribusi dalam PDB. Agar hal tersebut dapat benar terwujud, perlu diketahui faktor-faktor yang menjadi daya tarik bagi operator dan pelaku bisnis kapal pesiar.

Manzano et. all. (2014) mempelajari faktor-faktor penentu yang mempengaruhi kapasitas pelabuhan untuk menarik kapal pesiar di Spanyol. Kesimpulannya adalah lalu lintas pelayaran terkait dengan pelabuhan yang terletak di daerah padat penduduk dan dekat dengan bandara besar; pelabuhan tidak mengkhususkan diri dalam layanan lalu lintas kontainer saja tetapi juga berbagi fasilitas dengan menyediakan layanan lalu lintas kapal feri; serta pelabuhan memiliki kedalaman air minimum. Jumlah lalu lintas kapal pesiar yang dapat dihasilkan oleh pelabuhan juga terkait dengan populasi dan koneksi udara, bersama dengan daya tarik wisata dan fasilitas yang digunakan bersama dengan jenis lalu lintas pelabuhan lainnya, yaitu kapal roll-on roll-off (ro-ro) dan kapal feri. Terlepas dari ukuran dan populasi kota lokasi pelabuhan berada, temuan menunjukkan bahwa kota itu juga harus menarik bagi wisatawan dan pulau-pulau di sekitarnya juga memiliki kekhasan yang bisa menjadi magnet bagi wisatawan kapal pesiar.

Menurut penelitian Nugraha (2017), lalu lintas kapal pesiar adalah produk wisata yang kompleks dan pengelolaannya juga sama rumitnya. Manajemen lalu lintas kapal pesiar rumit karena tidak saja ditemukan adanya tanda-tanda konflik antara lalu lintas kapal pesiar dengan lalu lintas peti kemas, tetapi juga harus bersinergi dengan lalu lintas feri dan lalu lintas ro-ro. Memang, lalu lintas pelayaran saja mungkin tidak memberi cukup keuntungan/pendapatan untuk infrastruktur yang dibangun oleh perusahaan pelayaran. Seringkali, lalu lintas kapal pesiar tidak berjalan beriringan dengan lalu lintas kargo dan kontainer di banyak pelabuhan, sehingga diperlukan penanganan khusus agar ketiganya dapat beroperasi bersama secara sinergis.

\section{Pelabuhan Belawan menjadi pelabuhan utama sejak awal}

Pelabuhan Belawan adalah pelabuhan kelas utama di Kota Medan Sumatera Utara dan merupakan pelabuhan terpenting di pulau Sumatera. Pelabuhan ini berjarak sekitar $24 \mathrm{~km}$ dari pusat kota Medan dengan koordinat geografisnya $03^{\circ} 47^{\prime} \mathrm{N} \quad 98^{\circ} 42^{\prime} \mathrm{E} / 3.783^{\circ} \mathrm{N}$ $98.700^{\circ} \mathrm{E}\left(03^{\circ} 47^{\prime} 00^{\prime \prime} \mathrm{LU}\right.$ dan 98” 42” BT).

Cikal bakal lahirnya Pelabuhan Belawan adalah Labuhan Deli yang dulunya merupakan pusat pemerintahan Kerajaan Deli yang kesohor di kawasan Sumatera Timur. Bandar Labuhan Deli terletak di tepi Sungai Deli. Frasa 'Bandar' sendiri merupakan sebutan dari masyarakat suku Melayu Deli yang artinya labuhan atau pelabuhan. Karena masa itu yang berkuasa adalah pemerintah 
Kerajaan Deli, maka pelabuhan tersebut dinamai Labuhan Deli atau Bandar Deli.

Pelabuhan Labuhan Deli awalnya dibangun pada tahun 1890, untuk menyediakan lokasi di mana tembakau dapat ditransfer secara langsung antara jalur kereta api dari interior dan mendalam-draft kapal. Pelabuhan diperluas pada tahun 1907 dengan pembangunan bagian-bagian baru yang dimaksudkan untuk melayani pedagang Cina dan pedagang pribumi, serta menyediakan pelabuhan khusus untuk pengiriman orangorang Eropa.

Pada tahun 1915, Pelabuhan Labuhan Deli dipindahkan ke Belawan yang terletak di tepi Sungai Belawan. Hal ini disebabkan Sungai Deli kian dangkal, sehingga menghambat kapal masuk alur Sungai Deli menuju Labuhan Deli. Belanda membangun dermaga Belawan lama hingga mencapai panjang 602 meter dan lebar 9-20 meter. Oleh Belanda, dermaga Belawan lama dipergunakan untuk sandar berbagai jenis kapal, baik kapal kargo maupun kapal penumpang.

Pada awal abad kedua puluh bisnis pelabuhan berkembang maju, dengan pertumbuhan karet yang besar dan perkebunan kelapa sawit di Sumatera Utara. Pada 1920-an beberapa fasilitas pelabuhan utama dibangun. Pada tahun 1938, dalam perkembangannya, Pelabuhan Belawan menjadi pelabuhan terbesar di wilayah Hindia Belanda dalam hal nilai kargo. Volume kargo menurun drastis setelah kemerdekaan Indonesia, dan tidak mencapai tingkat pra-kemerdekaan lagi sampai pertengahan 1960-an.

Selain menjadi salah satu pusat niaga, Bandar Labuhan Deli kemudian dijadikan salah satu sentra penelitian para pemuka dan peneliti. Sebut saja, John Anderson seorang utusan Gubernur Penang WE Philips yang datang ke Labuhan Deli pada tahun 1823 dalam rangkaian survei politik ekonominya hingga ke pantai timur Sumatera untuk kepentingan Pemerintahan Kerajaan Inggris saat itu.

Karena aktivitas Pelabuhan Belawan semakin meningkat, pada awal tahun 1980, pemerintah mulai menyusun rencana pembangunan terminal peti kemas di Gabion, Belawan. Pembangunan tersebut didanai oleh Bank Dunia. Hasilnya, terminal peti kemas Belawan mulai beroperasi pada tanggal 10 Februari 1985. Awal tahun 2013, Pelabuhan Belawan mampu melayani arus bongkar muat peti kemas hingga 1,2 juta twenty-foot equivalent units (TEUs) per tahun dan akan meningkat secara bertahap hingga mencapai 2 juta TEUs per tahun.

Pemerintah melalui Kementerian Perhubungan lalu menata dan menjadikannya sebagai pelabuhan barang domestik. Sementara internasional akan dikhususkan ke Pelabuhan Kuala Tanjung. Kuala Tanjung dipilih sebagai pelabuhan hubungan internasional karena didukung dengan fasilitas. Di antaranya sisi dermaga yang dalam, sehingga bisa ditambat oleh kapal besar. Kemudian dari pelabuhan tersebut berpindah tak jauh dari pelabuhan Belawan lama. Tidak hanya pindah alamat namun namanya juga diganti menjadi Ujung Baru. Pelabuhan Ujung Baru ini sudah ada kurang lebih semenjak tahun 1970-an. Ternyata pelabuhan Ujung Baru juga mengalami pindah tempat dan pertukaran nama pelabuhan.

Pelabuhan setelah Ujung Baru, yaitu Pelabuhan Terminal Penumpang Bandar Deli. Terminal tersebut pindah tempat ke tempat pelabuhan Belawan Lama kembali. Pada 9 November 2015, Pelabuhan Terminal Penumpang Bandar Deli mulai beroperasional. Pelabuhan tersebut beroperasional setiap hari, selama 24 jam. Namun, untuk pelayanan kapal penumpang seminggu sekali pada hari normal. Apabila memasuki hari libur dan hari besar agama, maka pelabuhan Deli buka selama 24 jam karena ramainya pengunjung atau penumpang kapal.

Adapun fasilitas bagi penumpang di pelabuhan Terminal Penumpang Bandar Deli, tersedia tempat Check In Counter. Tempat ini merupakan tempat check in tiket yang sudah dibeli penumpang secara online atau dari Travel penyedia tiket. Bagi penumpang setelah check in tiket, penumpang dapat menunggu keberangkatan kapal atau datangnya kapal di Waiting Room. Tempat Waiting Room ini dilengkapi dengan Air Conditioner (AC) serta kursi dari besi untuk tempat duduk. Tidak 
hanya itu, di Waiting Room juga tersedia area khusus merokok, sehingga tidak mengganggu kenyamanan penumpang lainnya yang sedang menunggu waktu keberangkatan. Waiting Room di Pelabuhan ini tersedia dua tempat. Pertama di sebelah kiri dari tempat check in counter terdapat Waiting Room untuk kelas 1 dan 2. Sementara, di waiting room sebelah kanan dari tempat check in tiket, terdapat waiting room buat penumpang kelas Ekonomi.

Terminal Pelabuhan Bandar Deli tersebut juga menyediakan Kantor Kesehatan Pelabuhan (Port Health Office). Kantor ini dipergunakan untuk pelayanan penumpang yang mengalami sakit. Kemudian di Terminal Penumpang Bandar Deli juga ada disediakan tempat untuk bermain anak balita. Pelabuhan Terminal Penumpang Bandar Deli juga sudah dilengkapi dengan tangga garbarata yang bentuknya seperti leher angsa. Tangga ini berguna sebagai akses penumpang menuju kapal yang akan berangkat. Biasanya tangga garbarata ini ada di sebuah pesawat atau bandara, tetapi tangga garbarata ini sudah ada tahun 2016 di Pelabuhan ini.

Terminal peti kemas Pelabuhan Belawan pun dibangun untuk mendukung alih fungsinya sebagai pelabuhan bongkar muat. Berdasarkan data 2017, total arus bongkar muat barang mencapai 25,2 juta TEUs. Luas terminal peti kemas yang sudah ada, yaitu 127.518 meter persegi dengan panjang dermaga 550 meter, dan terus diperluas menjadi 157.700 meter persegi dengan panjang dermaga 350 meter dan selanjutnya menjadi luas 160.000 meter dengan panjang dermaga 350 meter.

Dengan fasilitas yang tersedia di pelabuhan itu, diharap laju bongkar muat barang terus lancar untuk mendorong percepatan distribusi barang demi kemajuan ekonomi masyarakat di daerah itu juga merambah ke daerah lainnya di Nusantara. Indonesia selayaknya memiliki industri maritim yang kuat dengan banyak lalu lintas kapal di lautnya. Kapal-kapal melayani laut dalam, pantai, danau dan sungai setiap hari, sehingga masyarakat Indonesia tidak akan dipisahkan oleh laut, karena laut sebenarnya adalah penyatuan, bukan pemisahan. Ini merupakan penegasan Indonesia sebagai negara maritim. Setidaknya semangat tol laut dari pemerintah untuk menghubungkan antar pulau saat ini bisa terus terwujud demi kemakmuran rakyat secara adil dan merata.

\section{Analisa dan Rekomendasi}

Sebagian besar wilayah di Indonesia memiliki iklim bersahabat dan bentang alam yang sangat mendukung bagi pengembangan wisata maritim dan khususnya wisata kapal pesiar/cruise. Wisatawan biasanya ingin merasakan iklim yang berbeda, karena karakteristik wisatawan adalah mencicipi sesuatu yang berbeda. Namun, untuk menarik lebih banyak lalu lintas kapal pesiar ke lautan Indonesia, hal tersebut tidak cukup. Sesuai hasil penelitian Manzano et all (2014), diperlukan juga pengembangan pelabuhan laut yang didukung oleh bandara besar dan terletak di daerah padat penduduk, serta pelabuhan tersebut harus dikelola dengan baik untuk dapat mengakomodasi pelayaran kapal pesiar, kapal feri dan lalu lintas kapal ro-ro.

Pelabuhan Belawan berada di Medan yang merupakan kota ketiga terbesar di Indonesia, serta memiliki dukungan fasilitas Bandara Kuala Namu dan jalan tol penghubung ke kota Medan yang baik. Sehingga, syarat kondisi lokasi seperti yang dikemukakan oleh Manzano sudah dapat dinyatakan terpenuhi dan dapat menjadi faktor pendukung. Sebagai kota yang multi kultur, Medan telah menjadi destinasi wisata yang menarik khususnya untuk wisata budaya dan wisata kuliner. Akan lebih baik jika kondisi ini tidak membuat terlena, namun harus terus dilakukan upaya pengelolaan wisata yang lebih baik disertai pengembangan dan pengemasan atraksi baru yang sesuai dengan tren dan issuissu strategis yang berkembang di industri pariwisata global.

Pelabuhan Belawan juga telah memiliki terminal dan area layanan yang terpisah antara layanan penumpang dan layanan kargo. Tantangan berikutnya bagi pengembangan Pelabuhan Belawan sebagai pelabuhan kapal pesiar sekaligus menjadi tantangan utama adalah sinergi pengelolaan dan peningkatan lalu lintas kapal penumpang, meliputi kapal pesiar, kapal feri dan kapal roro. Salah satu faktor krusial bagi peningkatan 
lalulintas ini adalah merubah mind set masyarakat Indonesia agar lebih bersahabat dan berorientasi pada wilayah maritim Indonesia. Ini merupakan tantangan besar sekaligus terberat karena pada kenyataanya masih banyak masyarakat yang berorientasi pada aktivitas di darat dan memandang laut sebagai jalur pemisah, bukan jalur pemersatu antar pulau.

\section{Referensi}

[1]. Brida, J.G. and Zapata, S. (2010). Cruise tourism: economic, socio-cultural and environmental impacts. Int. Journal of Leisure and Tourism Marketing, Vol. 1, No. 3, 205-226.

[2]. Indonesia. (n.d.). In Worldmark Encyclopedia of Nations. Retrieved from

http://www.encyclopedia.com/places/asi a/indonesian-political-

geography/indonesia

[3]. International Labour Organization (ILO). (2012). Strategic Plan Sustainable Tourism and Green Jobs for Indonesia Ministry of Tourism and Creative Economy of the Republic of Indonesia in cooperation with the International Labour Organization. Retrieved from https://www.cbd.int/financial/greenmark ets/indonesia-greentourism-ilo.pdf

[4]. Manzano, J.I.G., Fageda, X., and Laxe, F.G. (2014) An analysis of the determinants of cruise traffic: An empirical application to the Spanish port system Transportation Research, Part E 66, 115-125.

[5]. Nugraha, Tarsisius Catur Budi, (2017), Cruise Ship: the Backbone of Future Tourism Industry in Indonesia, Advances in Economics, Business and Management Research volume 28: 1st International Conference on Tourism Gastronomy and Tourist Destination (ICTGTD 2016)
[6]. Soshkin, M., (2015) Ocean \& Coastal Transportation in the US, IBISWorld, U.S.

[7]. Sun, Jiao, Y., Tian, P. (2011). Marketing research and revenue optimization for the cruise industry: a concise review. Int. Journal of Hospitality Management. 30, 746-755.

[8]. The Cruise Lines International Association. (2016). 2016 Cruise Industry Outlook. Retrieved from http://cruising.org/about-the-

industry/research/2016- state-of-theindustry

[9]. The Cruise Lines International Association. (2016). Asia Cruise Trends 2016. Retrieved from http://cruising.org/about-theindustry/research/asia-cruise-trends2016

[10]. The Cruise Lines International Association. (2015). 2015 Cruise Industry Outlook; Cruising to New Horizons and Offering Travelers More, Retrieved from http://cruising.org/aboutthe-industry/research/2015-state-of-theindustry

[11]. The Cruise Lines International Association. (2015). 2015 Annual Report. One Voice: Advancing Our Industry Together. Retrieved from http://cruising.org/abouttheindustry/rese arch/2015-annual-report

[12]. The Cruise Lines International Association. (2014). Economic Contribution of Cruise Tourism in Southeast Asia - 2014 Major Finding. Retrieved from http://cruising.org/docs/defaultsource/m arketresearch/2014-southeast-asiaeconomic-impact-study-nbsp---major findings.pdf?sfvrsn=0

[13]. Ward, D., (2015) Berlitz Cruising \& Cruise Ships (23rd ed.), Apa Publications Ltd., UK. 